OPEN ACCESS

Edited by:

Fei Chai,

Second Institute of Oceanography, State Oceanic Administration, China

Reviewed by:

Jason Michael Hall-Spencer, University of Plymouth, United Kingdom

Nova Mieszkowska, University of Liverpool, United Kingdom

*Correspondence: Jessica N. Cross jessica.cross@noaa.gov

Specialty section: This article was submitted to Global Change and the Future Ocean,

a section of the journal

Frontiers in Marine Science

Received: 21 December 2018 Accepted: 07 June 2019 Published: 02 July 2019

Citation:

Cross JN, Turner JA, Cooley SR,

Newton JA, Azetsu-Scott K,

Chambers RC, Dugan D,

Goldsmith K, Gurney-Smith H,

Harper $A R$, Jewett $E B$, Joy $D$, King $T$,

Klinger T, Kurz M, Morrison J,

Motyka J, Ombres EH, Saba G,

Silva EL, Smits E, Vreeland-Dawson J and Wickes $L$ (2019) Building the

Knowledge-to-Action Pipeline in North America: Connecting Ocean Acidification Research and Actionable

Decision Support.

Front. Mar. Sci. 6:356

doi: 10.3389/fmars.2019.00356

\section{Building the Knowledge-to-Action Pipeline in North America: Connecting Ocean Acidification Research and Actionable Decision Support}

Jessica N. Cross ${ }^{1 *}$, Jessie A. Turner², Sarah R. Cooley³, Jan A. Newton ${ }^{4}$,

Kumiko Azetsu-Scott ${ }^{5}$, R. Christopher Chambers ${ }^{6}$, Darcy Dugan ${ }^{7}$, Kaitlin Goldsmith $^{8}$, Helen Gurney-Smith ${ }^{9}$, Alexandra R. Harper ${ }^{10}$, Elizabeth B. Jewett ${ }^{11}$, Denise Joy ${ }^{12}$, Teri King ${ }^{13}$, Terrie Klinger ${ }^{4}$, Meredith Kurz ${ }^{11}$, John Morrison ${ }^{14}$, Jackie Motyka ${ }^{14}$, Erica H. Ombres ${ }^{11}$, Grace Saba ${ }^{15}$, Emily L. Silva ${ }^{14}$, Emily Smits ${ }^{12}$, Jennifer Vreeland-Dawson ${ }^{16}$ and Leslie Wickes ${ }^{17}$

${ }^{1}$ NOAA Pacific Marine Environmental Laboratory, Seattle, WA, United States, ${ }^{2}$ Cascadia Law Group, LLC, Olympia, WA, United States, ${ }^{3}$ Ocean Conservancy, Washington, DC, United States, ${ }^{4}$ University of Washington, Seattle, WA, United States, ${ }^{5}$ Department of Fisheries and Oceans, Bedford Institute of Oceanography, Dartmouth, NS, Canada, ${ }^{6}$ NOAA Northeast Fisheries Science Center, Highlands, NJ, United States, ${ }^{7}$ Alaska Ocean Observing System, Anchorage, AK, United States, ${ }^{8}$ Mid-Atlantic Regional Council on the Ocean, Williamsburg, VA, United States, ${ }^{9}$ Department of Fisheries and Oceans, St. Andrews Biological Station, St. Andrews, NB, Canada, ${ }^{10}$ Central and Northern California Ocean Observing System, Monterey Bay Aquarium Research Institute, Moss Landing, CA, United States, ${ }^{11}$ NOAA Ocean Acidification Program, Silver Spring, MD, United States, ${ }^{12}$ Department of Fisheries and Oceans, Ocean Science Branch, Ottawa, ON, Canada, ${ }^{13}$ Washington Sea Grant, University of Washington, Seattle, WA, United States, ${ }^{14}$ Northeastern Regional Association of Coastal Ocean Observing Systems, Portsmouth, NH, United States, ${ }^{15}$ Department of Marine and Coastal Sciences, Rutgers Center for Ocean Observing Leadership, Rutgers University, New Brunswick, NJ, United States, ${ }^{16}$ Gulf of Mexico Coastal Ocean Observing System, College Station, TX, United States, ${ }^{17}$ Southeast Coastal Ocean Observing Regional Association, Charleston, SC, United States

Ocean acidification $(\mathrm{OA})$ describes the progressive decrease in the $\mathrm{pH}$ of seawater and other cascading chemical changes resulting from oceanic uptake of atmospheric carbon. These changes can have important implications for marine ecosystems, creating risk for commercial industries, subsistence communities, cultural practices, and recreation. Characterizing the extent of acidification and predicting the ramifications for marine and freshwater resources and ecosystem services are critical to national and international climate mitigation discussions and to local communities that rely on these resources. Based on critical grassroots connections between scientists, stakeholders and decision makers, "Knowledge-to-Action" networks for ocean acidification issues have formed at local, regional and international scales to take action. Here, we review three examples of North American groups elevating the issue of ocean acidification at these three levels. They each focus on developing practicable, implementable steps to mitigate causes, to adapt to unavoidable change, and to build resilience to changing ocean conditions in the marine environment and coastal communities. While these first steps represent critical efforts in protecting ecosystems and economies from the risks 
posed by ocean acidification, some challenges remain. Sensitivity and risk to OA varies by region, species and ecosystems; priorities for action can vary between multiple and conflicting partners; evidence-based strategies for OA risk mitigation are still in the early stages; and gaps remain between scientific research and actionable decision-maker support products. However, the scaled networks profiled here have proven to be adept at identifying and addressing these barriers to action. In the future, it will be critical to expand funding for food web impact studies and development of decision support tools, and to maintain the connections between scientists and marine resource users to build resilience to ocean acidification impacts.

Keywords: ocean acidification, ocean observations, observation networks, knowledge-to-action, risk mitigation, decision support, climate resilience

\section{INTRODUCTION: ALARM BELLS, EARLY ACTORS, AND THE VALUE OF COLLABORATION}

Concern about ocean acidification as a scientific issue and a marine resource management concern has grown rapidly over the last decade, as the present and future impacts of this global ocean change have come into focus. Ocean acidification (OA) refers to the suite of chemical changes caused by the oceanic absorption of anthropogenic carbon dioxide $\left(\mathrm{CO}_{2}\right)$ from the atmosphere (reviewed at length in Gattuso and Hansson, 2011, and summarized in other papers in this volume). Briefly, the ocean absorbs about one-quarter of $\mathrm{CO}_{2}$ released annually by anthropogenic activities (Le Quéré et al., 2014). When $\mathrm{CO}_{2}$ dissolves in seawater it produces a weak acid, which lowers seawater's $\mathrm{pH}$ and increases its acidity. Average ocean $\mathrm{pH}$ has dropped by about 0.1 units since the start of the Industrial Revolution, corresponding to about a $30 \%$ increase in acidity (IPCC, 2013). Seawater $\mathrm{pH}$ is projected to drop 0.4 to 0.5 units by 2100 (Orr et al., 2005; IPCC, 2013).

The resulting chemical changes could have significant consequences for many marine ecosystems and marine ecosystem services. Calcifying organisms that build shells, skeletal structures, and hard parts from calcium carbonate frequently cannot build or maintain these carbonate structures under acidification, resulting in declines in growth and survival (e.g., Fabry et al., 2008). Even non-calcifying organisms are at risk: sensory, behavioral, and food-web impacts of OA have also been identified by the research community (Guinotte and Fabry, 2008; Munday et al., 2009; Simpson et al., 2011; Ou et al., 2015; Marshall et al., 2017). Metabolic responses to OA alter some organisms' energetic budgets (e.g., Francis Pan et al., 2015), and may even change the quality of seafood: both altered taste (Dupont et al., 2014) and lower protein, lipid, and carbohydrate contents (Lemasson et al., 2019) have been noted.

Worldwide, experts are concerned that progressing OA will cause cumulative ecosystem level shifts that put human communities at risk- possibly by reducing the overall economic value of commercial fisheries (Cooley and Doney, 2009; Narita et al., 2012; Clements and Chopin, 2016); eroding food security, especially for communities that rely on subsistence harvests as their primary source of protein (Garcia and Rosenberg, 2010;
Lam et al., 2014; Mathis et al., 2015), or driving cultural losses in native and tribal settings (Lynn et al., 2013; Metcalf, 2015; Wassillie and Poe, 2015). Ecosystem services such as capture fisheries, aquaculture, and traditional and recreational harvesting from key marine taxa and environments are expected to be highly impacted from high CO2 emissions (Gattuso et al., 2015) and other global change stressors, with implications of food security for vulnerable peoples.

These concerns have emerged in part because of early manifestation of real-world acidification impacts. In the early 2000 s, massive die-offs of oyster larvae in Pacific Northwest (PNW) hatcheries were attributed directly to acidification from anthropogenic carbon dioxide (Barton et al., 2015). This phenomenon threatened the Pacific oyster aquaculture industry, which supports over 3200 jobs and brings in \$270 million annually (Washington State Blue Ribbon Panel on Ocean Acidification, 2012).

Subsequent research has suggested that similar impacts could emerge in other areas that host vulnerable species, both reducing current populations and slowing growth in expanding industries. For example, commercial fishing in Bristol Bay, Alaska employs 12,400 people and generates 162 million dollars in labor income in each year. Most of these jobs come from harvests of sockeye salmon and other high-value species such as crab (McDowell Group, 2017), populations that are also susceptible to ocean acidification. Acidification directly affects calcification and growth of Alaskan crab species in laboratory studies (Long et al., 2013a,b), and behavior and predatorprey relationships of salmon (e.g., Ou et al., 2015), which could lead to population declines. Other concurrent stressors such as sea level rise will also affect coastal productivity and create conflict between terrestrial and aquatic food production systems; increased crop production or changes in precipitation patterns can lead to increased agricultural run-off into coastal systems, and further decreasing $\mathrm{pH}$ due to eutrophication (Cottrell et al., 2018).

Coral reefs are expected to be heavily altered. Combined with rising sea temperatures, some models project that $92 \%$ of coral cover will be lost by 2100 (Speers et al., 2016). This could lead to declines in fish landings for populations that rely on reefs for habitat (Hughes et al., 2017). Given the prevalence of coral reefs in the tropical Pacific, these impacts could be especially 
severe for Australia and the Pacific Islands (Johnson et al., 2015; Hoegh-Guldberg et al., 2017).

Population declines of this nature can be expensive. The projected value of coral reef tourism in Australia is approximately AU \$5-6 billion per year. Four of the ten most valuable marine fishery species in the United Kingdom are based on calcifying shellfish vulnerable to acidification (Le Quesne and Pinnegar, 2011). Losses in these fisheries alone could result in losses as high as $£ 379$ million pounds per year by the end of the decade, with additional losses as high as $£ 125$ million annually possible for the aquaculture industry (Cheung et al., 2012; Pinnegar et al., 2012). The Atlantic sea scallop industry represents more than $\$ 500$ million in annual landings for the United States East coast (National Marine Fisheries Service, 2012). Models predict that ocean acidification could reduce populations by as much as $50 \%$ in the coming decades (Cooley et al., 2015; Gledhill et al., 2015). Ocean acidification could also negatively impact scallop aquaculture in Australia (Richards et al., 2015) and Chile (Yañez et al., 2017).

Even in growing fisheries, ocean acidification is expected to have an impact. Potential increases in revenue from Arctic marine capture fisheries could reach nearly $40 \%$ in the coming decades (Lam et al., 2014). However, ocean acidification is expected to reduce the catch potential in those fisheries, slowing growth and other economic indicators. The consequences of OA are especially prevalent for Finland, Canada, and Greenland, where revenues are projected to decrease by more than $20 \%$. Across the entire Arctic region, slowed growth could represent losses of $\$ 390$ million per year in total economic output (Lam et al., 2014).

The description of these risks and vulnerabilities are based in part on the systematic response to acidification exposure developed as a rapid reaction to the economic fallout of the acidification-mediated PNW larval collapse in 2015. The immediate impact to the industry quickly drove research developments and policy action in Washington State and the PNW region that identified nascent risks to the industry, quickly changed practices to reduce exposure to those risks as much as possible, and supported preparation for future ocean changes. This collaborative, multidisciplinary, comprehensive regional response has informed the development of proactive steps implemented in other regions across the United States which aim to prevent the types of socioeconomic impacts as were seen in Washington. Most importantly, best practices are beginning to evolve around how OA knowledge and theory can be turned into action that prepares communities for the future.

Rooted in that initial response effort and the growing knowledge of $\mathrm{OA}$ risks around marine economic drivers worldwide, this paper describes the developing ocean acidification "knowledge-to-action pipeline" in North America (abbreviated here as the Pipeline). The Pipeline illustrates emerging sets of best practices to successfully mitigate and adapt to ocean acidification risks (Figure 1) that (a) improve the efficiency and speed by which actions yield results; (b) expand the breadth of community engagement and support for this work; (c) target specific needs; and (d) produce lasting benefits.
In general, these recommendations can be applied across diverse communities and varying situations and scales.

Relationship building is critical to each of these steps (Figure 2). In the next section of this paper, we present three case studies at local, regional, and international scales that provide particular evidence about the importance of successful partnership building. In the third section, we present case studies describing the development of actionable, concrete strategies to address $\mathrm{OA}$, based on these relationships.

In the fourth section of this paper, we synthesize the commonalities across these efforts to suggest that the Pipeline has two main elements: (1) partnership building and (2) action planning, each with clear implications for the development of existing and new ocean observation networks. We conclude the paper with a look at obstacles in the Pipeline, and how best to meet these challenges as applications expand in the future.

\section{FROM KNOWLEDGE TO ACTION: RELATIONSHIP BUILDING}

\section{The Earliest Days}

Impacts from ocean acidification first manifested in the Pacific Northwest United States, affecting the hatcheries that supply the entire Pacific oyster aquaculture industry on the United States West Coast (Barton et al., 2011). Extremely high larval mortality resulted in major seed production declines. Given that most oyster seed stock reared around the nation comes from larval hatcheries in the Pacific Northwest, the issue had farreaching impacts.

Immediately, marine users and resource managers began to search for solutions. Responding to this urgent need, a collaborative multi-disciplinary group of federal and academic scientists and private shellfish growers came together to identify the cause of the larval oyster mortality. This group grew out of several long-standing personal and professional relationships among federal and academic scientists and shellfish growers (Barton et al., 2015). Very soon, this small group grew into an interdisciplinary network of scientists, resource managers, industry and others from local, state, federal and tribal entities that came together to advance the understanding of ocean acidification and its effects on biological resources of the United States West Coast (Feely et al., 2012; Barton et al., 2015). Infrastructure support from existing national programs like Sea Grant and the U.S. Integrated Ocean Observing System helped ultimately to solidify these partnerships into the California Current Acidification Network (C-CAN).

At the same time, industry experts petitioned Washington State leaders at multiple levels of government for OA solutions. Two top-down outcomes followed: The industry group received NOAA funding for enhanced monitoring of OA (Barton et al., 2015), and the Washington State Governor convened the state's Blue Ribbon Panel on Ocean Acidification in 2012 to determine how to address the causes and consequences of ocean acidification. Importantly, panel members included state lawmakers, state resource managers and water quality experts, tribes, and impacted industry, and OA scientists, and they were 


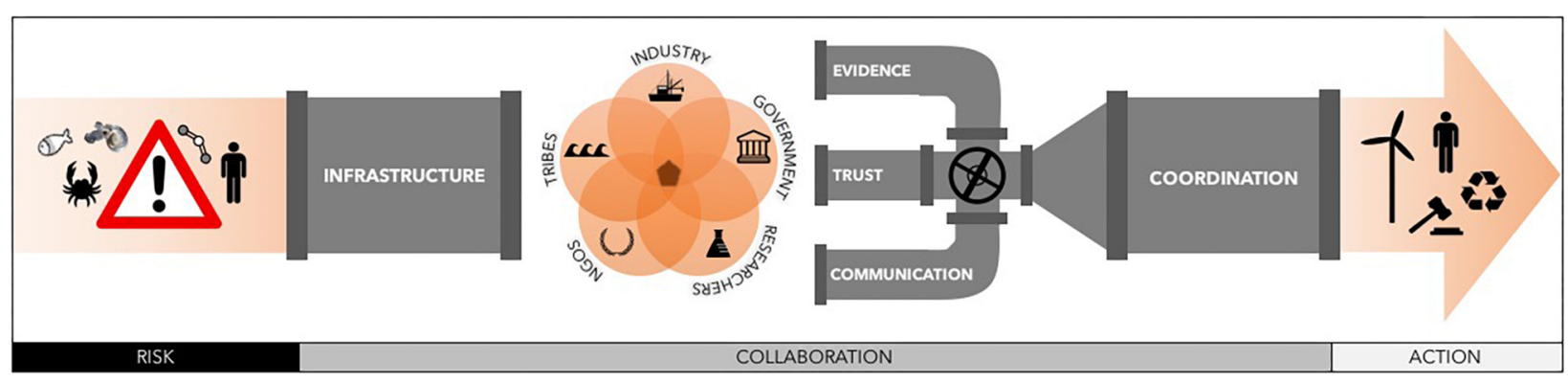

FIGURE 1 | Stages in the Knowledge-to-Action Pipeline. Information about risk is transferred through existing and amplified infrastructure to diverse stakeholders that all closely collaborate together. By building a body of evidence, mutual trust, and consistent communication practices, these bodies can coordinate to produce actions.

charged to identify concrete actions for the state to implement in response to the observed impacts of ocean acidification.

The scientific results and network emerging from C-CAN contributed greatly to the Panel's work. The Blue Ribbon Panel's report (Washington State Blue Ribbon Panel on Ocean Acidification, 2012) identified 42 consensus actions to directly assist in the rebuilding and protection of the local oyster industries, many of which have already been implemented. Since 2012, the Washington legislature has created and sustained a Marine Resource Advisory Council to maintain progress on specified actions. The group has demonstrated follow-through: a 5-year review was recently completed in 2017 (Washington State Blue Ribbon Panel on Ocean Acidification, 2017).

\section{The Importance of Investing Locally: United States Coastal Acidification Networks}

Building on the success of C-CAN, NOAA's Ocean Acidification Program and the U.S. Integrated Ocean Observing Systems (IOOS) Regional Associations have committed to growing this model around the country. Regional Coastal Acidification Networks (CANs) build public knowledge of the regional drivers and impacts of coastal and ocean acidification, coordinate stakeholder needs, and facilitate action through connections to scientists and policymakers.

Since the establishment of the California Current Acidification Network (C-CAN) in 2009, six operational CANs have formed around the country, including members from academia, industry, and both governmental and non-governmental organizations. The CANs provide a communication infrastructure to coordinate these diverse partners and equip United States regions with the tools needed to adapt to ocean and coastal acidification. CANs share specific elements, described below, which contribute to their sustained success.

\section{Elements of Successful CANs \\ Diverse partnerships}

CANs convene a variety of entities such as state agencies, researchers, industry, tribal members, and concerned citizens on an equal footing (Figure 2). A shared vision unites them; together they work to assess how changes in ocean and coastal

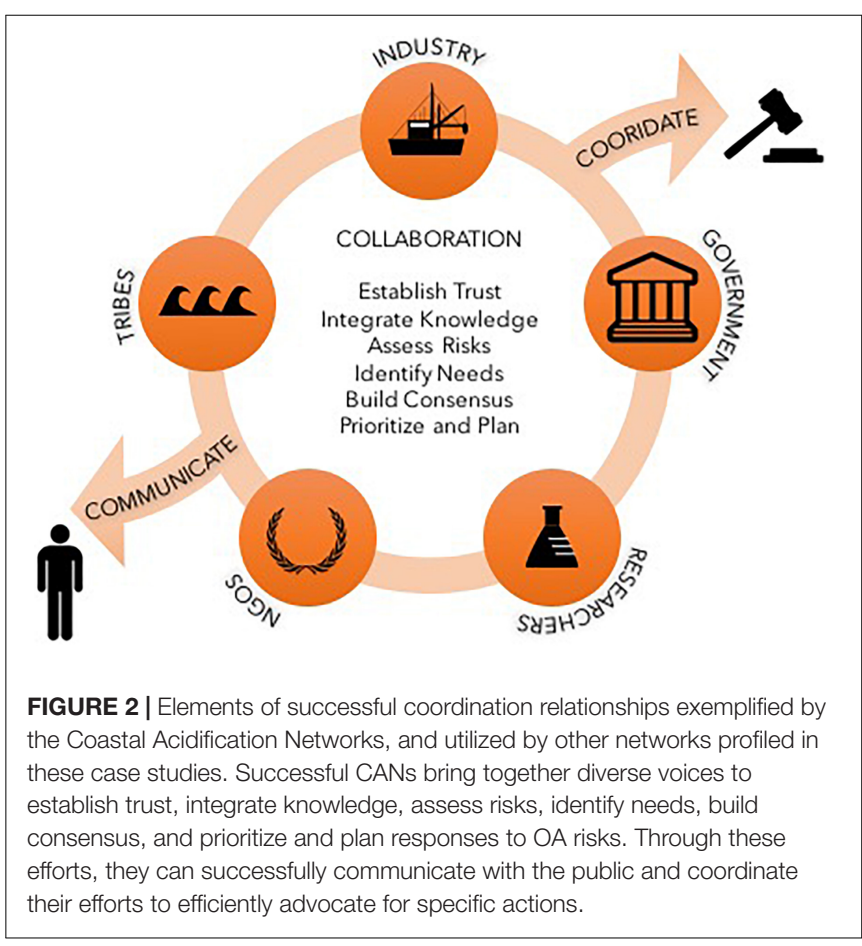

chemistry are manifesting in the region, identify gaps, and develop mitigation strategies. Because of their strong connections to communities, user groups, and local expertise, CANs are best positioned to help air community concerns and develop trust at the grassroots level among multiple sectors.

\section{Communication}

A key ingredient of a successful CAN is communication (Figure 2). The structure provided by the group helps facilitate ongoing conversations around the latest scientific results and observations, stakeholder concerns, and seeks to achieve participant consensus. Specifically, many CANs focus on communicating the state of the science, regional approaches to monitoring, and identifying vulnerable species and ecosystem hotspots. Disseminating this information and building relationships among different community sectors are based in 
good communication practices: many CANs use websites as an information hub for stakeholders, use an email list serve to foster communication among network members, and host webinar series to share stakeholder perspectives, research highlights, and management needs related to coastal and ocean acidification.

\section{Targeted working groups}

While communication strategies help educate stakeholders and decision makers about new and ongoing scientific research related to ocean acidification, one of the best tools developed by the CANs are regional working groups focused around particular stakeholders or risks. For example, The Northeast Coastal Acidification Network (NECAN) Industry Working Group was established to facilitate communication among industry members (including aquaculturists and fishermen) and leading ocean and coastal acidification experts to understand and respond to industry concerns about acidification risks. One outcome of this group already is the agreement by industry representatives that they need advance warning of any changes which might impact their business. NECAN has made developing this decision support output a central goal for the near future.

Continuing this theme, NECAN will be hosting a workshop at the Northeast Aquaculture Conference and Exposition (NACE) in the winter of 2019 where industry members can learn more about how acidification may impact their livelihoods in concert with other changes, and where scientists and federal agency representatives can hear from industry members about what advance information would be most useful to them. The conversation will be designed to help identify existing gaps in knowledge and monitoring that would impede development of the desired OA forecasts, and to help guide future research investment. The results from the Industry Working Group and the recommendations from NACE will be shared with the Maine State Commission and the New Hampshire State Commission through the NECAN Management and Policy Working Group to help shape future state-supported actions.

\section{Key Outcomes From CAN Collaborations}

The CAN experience has resulted in local research and monitoring plans that emphasize both research gaps and stakeholder needs, ensuring that developing research leads to actionable decision support products. Currently, the MidAtlantic Coastal Acidification Network (MACAN) is developing its regional plan to expand monitoring. Considerable uncertainty still exists for Mid-Atlantic species around acidification effects on individual fitness, biodiversity, and predator-prey interactions. Highly variable observed responses, small-scale laboratory experimental scenarios, and limited species-specific and ecosystem-scale acidification studies limit researchers' ability to assess present and future impacts on ecosystems and coastal communities. Additional environmental stressors and the acclimation or adaptation potential of individuals and populations could likely play opposing roles under acidification scenarios. Whether this results in net exacerbation or alleviation of ecosystem stress is as yet unknown. However, to what extent the relative contribution of these drivers will impact the overall Mid-Atlantic ecosystem needs to be investigated. To this end,
MACAN has identified existing monitoring efforts, clear research gaps, relevant research priorities, and recommendations for optimizing additional monitoring, due for release in 2019.

\section{Recommendations for Local Collaboration Networks}

Truly effective collaboration is key to the success of the regional CANs. At every step, the CAN recipe depends on the ingredients discussed above to be successful: diverse partners, communication, and targeted working groups (Figures 1, 2). As a result of this collaboration, CANs have become very successful local-to-regional grassroots organizations. Others in the ocean observing community seeking a knowledge-to-action approach at this level should consider the following recommendations:

- Bring together a collaborative and diverse team around a given issue (no more than 15 people). The leadership team should include multidisciplinary science perspectives and multiple private sector entities to ensure that all stakeholders have a voice in the CAN.

- Compile and assess regional needs through stakeholder engagement at all levels (government, academia, non-profit, industry, etc.).

- Assess existing efforts and identify gaps and areas of opportunity.

- Fill information gaps through strategic funding efforts.

- Continue engagement with stakeholder groups, keeping them up to date, as well as encouraging additional input.

\section{Regional Collaborations That Cross National Borders: A Framework for Action on Western Arctic Acidification}

Many of the lessons learned from the early CAN efforts are already being applied at a much larger scale. Here, we profile a relatively young observational network for acidification that is incorporating these recommendations as it starts to scale up: the joint Canadian-United States Collaborative Framework for Western Arctic Acidification.

Structures that coordinate research in vulnerable, rapidly changing regions where knowledge is lacking can be invaluable to advancing research and action. In the Arctic, acidification research is at a much earlier stage than in other areas, given that harsh conditions and remote territory limits data gathering, and sea ice presents a serious hazard to long-term monitoring equipment. Nevertheless, acidification in the Arctic is progressing rapidly (Mathis et al., 2015; AMAP, 2018; Cross et al., 2018) and the region is commonly referred to as a bellwether for ocean acidification impacts (Fabry et al., 2009).

In June 2016, Canadian Prime Minister Justin Trudeau, American President Barack Obama and Mexican President Enrique Peña Nieto met in Ottawa for the North American Leaders Summit. Participants recognized the need to provide global leadership and enhanced cooperation on the impacts of climate change on oceans and marine ecosystems. In support of the international commitments made at this Summit, members of Fisheries and Oceans Canada (DFO) and the United States National Oceanic and Atmospheric Administration (NOAA) held an initial meeting in Canada in September 2016 to 
discuss impacts of $\mathrm{OA}$ on marine resources, share research methodologies for OA monitoring and mitigation, and identify opportunities for collaborative efforts.

Following this auspicious start, the DFO-NOAA Ocean Acidification Coordination Committee was formed in 2017, operating under an existing Environment Canada and Climate Change - NOAA Memorandum of Understanding. A finalized Collaboration Framework on Ocean Acidification formed two Working Groups: (1) the Monitoring Working Group, and (2) Research, Experimentation and Modeling Working Group, both of which are co-led by DFO and NOAA scientists. Membership of each group consists of DFO, NOAA or NOAA-funded scientists with expertise including: biogeochemical, physical, biological and ecosystem modeling; observation and data synthesis; and, experimental and field biological effects research.

So far, the key successful actions of the DFO-NOAA Collaboration Framework have come from the working groups. Much like the CAN model for establishing regional observation networks, both groups are beginning their efforts by developing inventories of monitoring, biological research and modeling efforts that are underway. To facilitate collaboration, both groups are also developing best practices for monitoring or research and experimentation tailored to bilateral concerns, developing OA communication activities and results between DFO and NOAA, and promoting knowledge sharing via joint meetings and collaborative opportunities.

The Monitoring Working Group specifically aims to establish priority areas including shared areas of concern, such as regional hotspots; coordinate cruises; and identify expertise and infrastructure gaps hindering geochemical understanding of OA. The Research, Experimentation and Modeling Working Group specifically aims to identify shared fauna of concern and appropriate actions to take; and identify gaps in expertise, biological research or infrastructure that hinder biological understanding of OA impacts and reduce modeling accuracies.

As the group focuses on the goals of two federal agencies, existing infrastructure to communicate and address stakeholder needs are relied upon. Fortunately, close connections already exist between the leadership and working group participants and regional stakeholder coordinating groups, such as the CANs. In particular, the Alaskan and Northeastern CANs have been a critical resource for educating researchers and the federal leadership. Helpfully, the CANs have a close and deliberate connection to NOAA. Additionally, many of the working group participants also participate in other Arctic coordination efforts, including the Synthesis of Arctic Research (SOAR) Program, the Inter-agency Arctic Research and Policy Committee (IARPC), working groups of the Arctic Council, such as the Distributed Biological Observatory Program (DBO), and the Arctic Marine Assessment Programme (AMAP).

These outside groups have all identified key hotspots and ecosystems that may be affected by ocean acidification, and which council the DFO-NOAA working groups on their recommendations. For example, the recent Arctic Marine Assessment Program (AMAP) report on ocean acidification profiled five ecosystems that may be at risk from ocean acidification (AMAP, 2018). The monitoring working group is advocating for an expansion of the Distributed Biological Observatory hotspot program that will address North American Arctic acidification concerns outlined in the AMAP report.

\section{Recommendations for Regional Collaboration Networks}

The key benefits of this federal bilateral initiative are to advance and integrate multidisciplinary ocean acidification science efforts, promote collaboration to enhance program delivery, and to facilitate effective resource management in a changing ocean. Coordination that crosses international boundaries in particular can break down data silos and increase information sharing and access.

- Leverage existing diplomatic infrastructure that enables easy collaboration across borders.

- Build specific coordination infrastructure for the key research topic.

- Assess existing efforts to identify gaps and opportunities for growth, encouraging synthesis and data sharing agreements between entities.

- Create bridges to diverse stakeholder organizations within each entity that help generalize priorities across local regions and identify important regional priorities.

\section{From Regional to Global: International Alliances}

The Pacific Coast Collaborative (PCC), representing the United States states of California, Oregon, Washington, and the Canadian province of British Columbia, was formed in 2008 when the leaders of the participating states and province agreed to work together as a region on energy, climate, and ocean health issues. Following the PNW larval oyster losses in the $2000 \mathrm{~s}$ that gave rise to WA state action supported and informed by C-CAN, the PCC has been working to address the causes and impacts of ocean acidification together as a region since 2010, including calling for more investment in scientific research and monitoring.

In 2013, the PCC member jurisdictions convened the West Coast Ocean Acidification and Hypoxia Science Panel (Chan et al., 2016), responding directly to recommendations put forward by the Washington State Blue Ribbon Panel. Comprised of scientists from across the region, the WCOAH Panel focused on ocean acidification and hypoxia impacts on the ecosystems and economies across the west coast of North America and recommended a series of local and regional strategies for addressing the challenge. In addition to recognizing the central importance of mitigating carbon emissions in developing solutions, the WCOAH Panel stressed the value of improving the West Coast monitoring enterprise of both physical and biological factors. The WCOAH Panel recognized that a rigorous understanding of $\mathrm{OAH}$ trends and biological responses would allow for more effective and strategic investments in adaptation and mitigation measures.

To make progress on this WCOAH Panel recommendation, the PCC convened the Joint Ocean Acidification and Hypoxia Monitoring Task Force (Task Force) in 2016, in partnership with 
the federal Interagency Working Group on Ocean Acidification (IWG-OA). The goal of the Task Force was to inventory the OAH monitoring infrastructure along the North American Pacific Coast and provide easy public access to the results.

Completed in 2018, the monitoring inventory now contains records from over 125 participants describing over 200 projects from Alaska to Baja California. The monitoring efforts described in the inventory are capturing trends in $\mathrm{OAH}$ occurring across the region and helping scientists and decision-makers better understand and respond to potential impacts to key species and ecosystems.

The monitoring inventory also sets the stage for a collaborative region-wide gap analysis. This analysis will inform the design of a West Coast Integrated $\mathrm{OAH}$ Monitoring network that efficiently leverages existing assets and supports subsequent strategic monitoring investments. The ultimate goal is to have a functioning coast-wide monitoring network that effectively answers management questions about ocean acidification and hypoxia and informs actions that reduce impacts, improve resiliency and support adaptive management.

Responding to a subnational call for climate and ocean leadership unleashed by the COP21 Paris Climate Agreement negotiations in 2015, and to advance the impacts of existing state and regional collaboration on an international scale, the West Coast jurisdictions formed and launched the International Alliance to Combat Ocean Acidification (OA Alliance) in December 2016. The OA Alliance brings together governments and partners concerned about the impact of carbon on our oceans and are ready to take meaningful actions to address these changes (International Alliance to Combat Ocean Acidification, 2016).

The intent of the OA Alliance is to motivate governments to proactively respond to the impacts of ocean acidification by charting a course of action for sustaining coastal communities and livelihoods. OA Alliance members work together to raise awareness about ocean acidification. They commit to take individual actions that address the environmental and economic threat posed by ocean acidification within their region by creating their own unique OA Action Plan. Members are also calling for emissions reductions and ocean adaptation and resiliency actions under applicable climate frameworks like the United Nations Framework Convention on Climate Change (UNFCCC) and the United Nations Sustainable Development Goals (UN SDGs.) Ultimately, the best mitigation plan for ocean acidification is to drastically curb carbon emissions, which will require ongoing commitments to international collaboration.

Since its launch in December of 2016, the OA Alliance has grown to over seventy members including eleven national governments, eight states, two provinces, six tribal nations, and four cities, along with research institutions, businesses and NGOs.

The OA Alliance is not alone in its efforts and has strategically identified and built relationships with strong partners and potential new members each month, ultimately securing commitments to collaborate across organizations and increasing commitments to join. The OA Alliance has been steadily increasing the number of government and affiliate members that are regularly engaged with $\mathrm{OA}$ Alliance efforts which provides diversity of membership from members focused on impacts from the Arctic to the Indian Ocean.

Other organizations also support international ocean acidification research and action. The Ocean Acidification International Coordination Centre (OA-ICC) specifically promotes the development of data management tools and standardized methodologies and best practices for ocean acidification research. Housed under the International Atomic Energy Agency, the OA-ICC focuses on peaceful applications of nuclear and isotopic techniques (e.g., geochronology; paleo-climatology; isotopic uptake rates) for ocean acidification research. This group has also formed extensive collaborations and extra-budgetary coordinated research projects that support research into the biological and social effects of ocean acidification. We also encourage interested readers to consider the comprehensive review of the Global Ocean Acidification Observing Network (see Jewett et al., 2019 this volume). Briefly, this organization focuses on $\mathrm{OA}$ science in order to document the status and progress of ocean acidification on the global scale and in coastal environments, to understand the chemical drivers and ecosystem-level impacts of ocean acidification, and to coordinate members to provide spatially and temporally resolved biogeochemical data necessary to optimize modeling for ocean acidification.

\section{Creating Decision-Maker Support Tools}

While organizations like GOA-ON and the OA-ICC help to coordinate research that is critical for the ultimate creation of decision support tools, the OA Alliance is unique in that it specifically focuses on governmental action on the international scale. Critical to its mission, the OA Alliance has engaged with members in the development of jurisdictional OA Action Plans that will describe real, tangible actions that governments will take to respond to the threat of ocean acidification. The OA Alliance has made international commitments with the UN SDG 14.3 and at the 2017 Our Ocean Conference to support the development of twenty OA Action Plans by the end of 2019. The Alliance is well on pace to meet that goal with Washington, California, Oregon, and New Zealand Action Plans all completed or nearly completed, and several more to follow including those from City of Vancouver in British Columbia, Netherlands and Fiji.

To aid governments in this process, the OA Alliance created an OA Action Plan Toolkit (International Alliance to Combat Ocean Acidification, 2017), a strategic process for starting to develop a plan. The toolkit draws from a compendium of best practices and recommendations stemming from published state, regional, and national ocean action plans, as well as ocean acidification action plans or ocean acidification commission recommendations in the United States. It makes recommendations for actions across five categories: (1) advancing scientific understanding; (2) mitigation; (3) adaptation and resiliency actions; (4) public awareness and outreach; and (5) elevating climate related impacts to oceans within international climate frameworks. The OA Alliance encourages member 
governments to consider "right sized" and locally specific actions within each category.

The OA Alliance has also hosted member-driven webinars on topics including using the OA Action Plan Toolkit, member updates on their action planning processes, a tutorial of the newly launched OA Information Exchange hosted by NOAA Ocean Acidification Program, techniques and pilot projects focused on carbon sequestration through the use of submerged aquatic vegetation, existing monitoring networks and tools for beginning new monitoring sites and expanding regional networks, incorporating ocean acidification adaptation and resiliency actions into Nationally Determined Contributions called for by the Paris Climate Agreement, and how actions by cities can address ocean acidification locally.

What has become increasingly clear through the rapid growth of the OA Alliance in just 2 years is the interest from high-level policy and decision-makers to become more engaged with scientists who will help them better understand local impacts to key marine resources within their regions. Government members of the OA Alliance are learning from each other about the policy frameworks they will use to address a suite of mitigation, adaptation and resiliency strategies that are needed to robustly respond the potential impacts of ocean acidification, while also managing for forcemultiplying factors of temperature and dissolved oxygen changes over time.

While the OA Action Plan provides a platform for governments to think about various policy implementation pathways, including increased funding for more advanced monitoring, it's not intended to be a prescriptive set of policies or exactly replicable framework that will work for all governments. Increasingly the priority for member governments joining the $\mathrm{OA}$ Alliance is to learn about processes for convening the right set of actors that will produce a series of local or regional recommendations and then, importantly, how existing management frameworks can incorporate and sustain new investments and actions over time.

Just as some ocean acidification science is in beginning stages, policy response and management discussions are also in beginning stages, making early and frequent collaborations across government, scientists, and impacted industry at a regional level all the more beneficial.

\section{Recommendations for International Collaboration Networks}

The strength of the OA Alliance comes from members working together (i.e., Figure 2), committing to taking concrete action and sharing best practices for effective mitigation and adaptation management frameworks for ocean acidification at a local, regional and international level. The OA Alliance serves a unique role by inspiring political commitments and policy actions through the high-level leadership of its government members. The following recommendations are taken directly from the OA Alliance mission statement:
- Create a coalition of governments and partners at all stages of OA learning to elevate the visibility and importance of ocean acidification in public discourse and policy development.

- Support governments to take meaningful actions to address changing ocean conditions by creating actionable decision support products.

- Push for inclusion of strong ocean protection provisions in international climate agreements and other relevant frameworks to build sustained support for addressing this global problem.

- Advance scientific understanding and expand public awareness and understanding of acidification.

The Global Ocean Acidification Observing Network (GOA$\mathrm{ON}$ ), formed in 2012, provides input to the last of these recommendations (see Tilbrook et al., 2019 this volume; Newton et al., 2015). Organized at the global scale, GOA-ON has assembled a network of over 500 scientists from more than 80 countries, and reaches out to members all over the world who are working to understanding OA on local to global scales. Through this collaborative international approach, GOA-ON seeks to document the status and progress of OA in openocean, coastal, and estuarine environments, to understand the drivers and impacts of OA on marine ecosystems, and to provide spatially and temporally resolved biogeochemical data necessary to optimize modeling for OA parameters. Accordingly, GOA-ON works to provide the critical Knowledge piece of the Knowledgeto-Action Pipeline.

Lessons learned from existing international collaboration efforts include:

- The power of government and non-government collaboration and partnerships within one region;

- The importance of engaging political leadership at a highlevel;

- Focus on long-term implementation mitigation, adaptation and resiliency strategies over time;

- Government to government info- exchange is invaluable and appreciated, even if regions are not experiencing exactly similar issues or managing for the same resources.

\section{FROM MONITORING NETWORKS TO OA ACTION PLANS}

A case study from California illustrates how the OA Alliance is providing a platform for governments to engage in the Knowledge-to-Action pipeline.

The California Ocean Protection Council, in cooperation with the California Ocean Science Trust, has undertaken the development of a State of California Ocean Acidification Action Plan (Phillips et al., 2018). The policy and management action plan is the first of its kind for the state of California and was developed within the framework of the OA Alliance.

California's plan relies heavily on scientific data as a basis for action, such as data inputs and information on monitoring instrumentation, research on species sensitivity, oceanographic 
and ecosystem modeling, social science, education, and communication provided through federal partnerships with NOAA's regional observation networks established through the U.S. Integrated Ocean Observing System (IOOS) and its local Regional Associations-the Southern California Coastal Ocean Observing System (SCCOOS) and the Central and Northern California Ocean Observing System (CeNOOS). The state's action plan provides a concrete vision and set of trackable actions for making progress to better understanding and address critical threats to the productivity, ecology, and economic benefits derived from the state's coastal and nearshore marine ecosystems. In so doing, it serves as a model for other jurisdictions (national and subnational) seeking to act on ocean acidification.

The Action Plan outlines six strategies that map strategically with OA Alliance Call to Action (International Alliance to Combat Ocean Acidification, 2017):

Strategy 1 - Prepare for the Full Range of OA Risks and Impacts.

Strategy 2 - Activate Responsible Elements of State Government.

Strategy 3 - Reduce the Pollution that Causes OA.

Strategy 4 - Deploy Living Systems to Slow OA and Store Carbon.

Strategy 5 - Build Resilience of Affected Communities, Industries, and Interests.

Strategy 6 - Engage Beyond State Boundaries.

Actions proposed in the plan include, but are not limited to:

- Conduct a statewide vulnerability assessment to identify the risks OA poses to the California's biological resources, communities, and economies, within the context of other ongoing environmental changes and hazards, and to identify priorities and options for action to improve societal adaptive capacity.

- Design and make targeted investments in a monitoring and observation (M\&O) system optimized to deliver decisionrelevant information that serves user needs.

- Fully integrate OA into California state government policies, planning, and operations.

- Systematically integrate OA and coasts and oceans into California's GHG emissions reduction program.

- Implement a coordinated and strategic statewide approach to restoring, conserving and assisting in the migration of seagrass meadows, kelp forests, and salt marshes to achieve multiple state goals.

The scope of the action plan allows its application to be hyperlocalized, regional, or even global- calling for specific inventory and prioritization of assets and actions across multiple scales. Capacity for demonstrative power and information exchange are also built into the process:

The primary purpose of this Action Plan is to provide a roadmap for the State of California to take tractable and strategic actions and make targeted investments to reduce and prepare for the impacts of OA. Although it focuses on California's particular needs and opportunities, these are cast within a regional, national, and international context, where appropriate, to achieve state goals, advance global efforts and collaboration, and help other jurisdictions move forward on this challenging problem." (Phillips et al., 2018).

While this case study highlights California, there is similar progress in several states, which also benefit from synergies between regional and national partnerships. For instance, New York, an OA Alliance United States state member, along with Virginia and Hawaii, is making quick progress with the August 2018 announcement of State Ocean Acidification Task Force to evaluate impacts on the state's coastal waters and examine adaptive strategies. In this process, it will be essential that IOOS's Regional Associations there (Northeastern Regional Association and Coastal Ocean Observing System, NERACOOS, and Middle Atlantic Regional Association and Coastal Ocean Observing System, MARACOOS) and the associated Northeast Coastal Acidification Network (NECAN) and the Mid-Atlantic Coastal Acidification Network (MACAN) continue to build and maintain a network that helps inform policy makers and task force members charged with interpreting existing data and implementing further recommendations for investments and actions. Similar progress in other United States states has harnessed partnerships where Coastal Acidification Networks also in Alaska, the California Current, the Southeast, and Gulf bring together scientists, state and local agencies, tribes, and local stakeholders, working through the NOAA Ocean Acidification Program (OAP) and IOOS Regional Associations. Such efforts benefit from the specification of local needs and impacts that are relevant to the region, as well as from the consistency afforded through NOAA's OAP funding of observing efforts via the IOOS Regional Association assets.

\section{DISCUSSION}

\section{Critical Elements in the Knowledge-to-Action Pipeline}

The networks reviewed above are difficult to evaluate singly, as each activity builds on prior work. Cross-pollination is unavoidable, because some activities have been modeled directly on prior activities, while others have called on some of the same experts. Nevertheless, common themes re-appear in each activity, seeming to contribute to their success in driving forward stepwise action to address the impacts and causes of OA, building local communities committed to participating in a collective search for solutions, and creating sustained momentum at multiple organizational scales.

The collected examples here identify the elements of success that support the knowledge-to-action pipeline (Figure 1):

1) Urgent need. OA Action is strongly motivated by the need to protect and sustain marine resources that provide benefits to human communities, such as shellfish aquaculture industries or Arctic ecosystems.

2) Interdisciplinary partnerships. Bringing together a wide range of experts-not just on $\mathrm{OA}$ science, but also 
on marine resource management, policy development, local industry needs, and community priorities-produces broader base of support and a more comprehensive set of solutions that are specifically tuned into community needs and priorities.

3) Shared goals. The interdisciplinary partnerships mentioned above have helped develop broad, collective visions of what OA preparation includes. Work has then commenced to pursue those goals via working groups, targeted activities, and more. Identifying and committing to these shared goals has also supported the development of stepwise action as well as activities that require long-term commitments (e.g., long-term monitoring or adaptation activities).

4) Leveraging existing coordination structures. With the existence of so many scientific and regional coordination bodies, it would be ineffective to set up several new OA coordination activities. As a result, the Pipeline has made wise use of existing networks, such as the IOOS regional associations and the Pacific Coast Collaborative, building out the number of networks only when necessary via activities such as the DFO-NOAA OA Coordination Committee and the OA Alliance.

5) Communication. It cannot be emphasized enough that regular, open communication has been critical to every element of the Pipeline described above. Creating trust among different stakeholder groups and developing a shared vision requires honest and wide-ranging discussions. Likewise, the commitment of assets to take action, as national and state governments are doing, requires negotiations and sometimes compromise to ensure equitable participation.

\section{Obstructions in the Pipeline}

Despite the progress made to date on converting OA knowledge to action, barriers to implementation still exist. Uncertainty is a primary obstacle, touching every element of the Pipeline, from the scientific understanding of $\mathrm{OA}$, to responses of communities, effectiveness or feasibility of actions taken to address OA, and more. Prioritization of OA action is also a challenge given the multiple urgent competing priorities that leaders must consider. The feasibility of any action must be considered as well. Finally, the scalability of actions is also relatively untested and frequently not able to be clearly predicted.

\section{Uncertainty}

In addition to scientific uncertainty about how acidification affects marine resources and systems of interest (e.g., Kroeker et al., 2010), there is still a great deal of uncertainty surrounding the actions that can be taken to mitigate ocean acidification risks. Each intervention needs extensive testing to ensure it does in fact mitigate acidification or its impacts on the system of interest. Additionally, the economic cost and scalability of any intervention must be understood to provide a practical option for resource managers and industry leaders.

The most thoroughly tested set of interventions concern bivalve shellfish aquaculture. In situ monitoring and water chemistry amendments at shellfish hatcheries have been the focus of intensive study for nearly a decade (Barton et al., 2011, Barton et al., 2015) and can now be implemented at hatchery scale. In addition, co-culture of kelp and shellfish in aquaculture installations to decrease $\mathrm{OA}$ is being piloted in several locations. Phytoremediation research to support shellfish aquaculture focuses mainly on evaluating the appropriate physical setting for this type of intervention and other practical limits, like seasonal and economic limits.

Because of the uncertainty associated with impacts of ocean acidification on marine systems and the risk-to-reward balance of interventions, many groups are striving to promote proactive management rather than reactive management. While in some cases reactive management can be successful-consider the recovery of the Pacific Northwest shellfish hatcheries-chronic acidification, especially when combined with other stressors, may eventually be more difficult to manage. Preventing future impacts generally has a much lower economic cost than waiting for impacts to emerge, suffering the consequences, and attempting to both recover and mitigate future risk at the same time. Seung et al. (2015) used a bioeconomic model to compare proactive and reactive management to OA. According to their simulations, proactive management could maintain a sustainable crab fishery in Bristol Bay, Alaska. By contrast, a reactive management strategy led to the collapse of the crab population and closure of the fishery by mid- to late century. In Alaska the proactive viewpoint has been persuasive, helping to elevate the demand for action on acidification and yielding dedicated funding support for targeted fisheries management products.

\section{Prioritization}

For communities experiencing the impacts of climate change on multiple fronts, it can be difficult to demonstrate that acidification should be a priority. For communities along Alaska's northern coasts, through the Bering Sea and Bering Strait region, coastal erosion is an immediate and existential threat for some communities like Shishmaref. While ocean acidification may pose a threat to the ecosystem and subsistence assets these communities depend on, housing security is a much more urgent concern. Therefore there may be trade-offs to consider.

Reducing uncertainties around interventions' effectiveness, riskiness, and cost may help leaders make better decisions in light of competing priorities, as well as account for the political and economic dynamics which are most relevant to them (Cooley et al., 2016; Albright and Cooley, 2017). However, even when the community is united around ocean acidification risk, it can be difficult to balance the priorities of multiple stakeholders. Regions may also have to choose among vulnerable areas when deciding when and where to commit resources.

\section{Feasibility}

The best way to combat ocean acidification is by reducing $\mathrm{CO}_{2}$ emissions. Numerous analyses showing that $\mathrm{CO}_{2}$ emissions reduction will benefit the ocean have come from the scientific community in recent years (e.g., IPCC, 2014; Gattuso et al., 2015). However, large scale $\mathrm{CO}_{2}$ emissions reductions have been slow materialize the international level. To 
help address this, the OA Alliance is attempting to consolidate the voices of leaders internationally calling for national and subnational governments to reduce emissions in order to slow the pace of ocean impacts and respond now to local climate related threats to ocean resources. This work is also connected to regional movements, which also benefit from smaller and localized actions-such as filling regional knowledge gaps in addition to making their own commitments to reducing $\mathrm{CO}_{2}$ emissions. In these examples, the feasibility of different actions at different scales is factored into the recommendations for actions that are appropriate at each scale.

\section{Scalability}

Plans to address acidification within a particular region may not be applicable to other regions or across short and long time scales. Moreover, there are very few "complete" acidification stories that demonstrate the OA-related benefits of a particular action. Given that no single OA action plan can be considered a panacea, this increases the cost and the effort associated with the development of a local or regional OA adaptation plan, as a considerable amount of planning may be required. Organizations such as those reviewed here have helped share details of plans developed by one jurisdiction with others that wish to take action (In fact, this is one of the formal goals of the OA Alliance). In cases where plans developed by one region are applied elsewhere or over different time-scales, translation assistance is needed by OA experts. Precedent matters, especially for legislative actions concerning ocean acidification, and having evidence of success in one region may speed the adoption of actions in another region.

\section{Looking Forward}

In truth, combinations of actions and interventions are required, as there is no one-size-fits-all solution to address $\mathrm{OA}$ other than reducing global atmospheric $\mathrm{CO}_{2}$ levels. Preserving the functions of ecosystems at risk from OA requires the application of an array of interventions, because not all interventions preserve all elements of an ecosystem (Albright and Cooley conference paper). Commitments to see interventions through to fruition must be secured early and sustained over time, as some actions take a much longer time than typical funding cycles or even political office terms (e.g., development of seasonal OA forecast model on West Coast has taken 10 years). This may require frank, difficult conversations about the priorities of leaders and communities, so they can seek to reconcile urgent, short-term needs with longer-term precautionary planning and development.

The key to overcoming all four of the challenges discussed above is increased communication and multi-disciplinary partnerships at the local, regional and international level. Creating networks that apply the best practices of the Pipeline can lead to rapid action on ocean acidification. Ongoing collaboration from the earliest research stages can help increase the likelihood that decision makers have the knowledge they need available in a useful and understandable format.

The positive impacts of the Pipeline have reached beyond the resource users and managers directly affected by OA. In a little more than 10 years, ocean acidification has matured from a niche issue recognized by a handful of academic and federal scientists to an issue discussed in mass market media and anticipated by marine resource users and managers, elected officials, and the public. This result has followed from a coordinated, concerted communication effort by the scientific community and advocacy organizations that was paired with intentional cultivation of partnerships among researchers and information users.

Bottom-up, self- or peer-organizing efforts have been extremely effective at engaging new constituencies and turning ocean acidification into a publicly recognized issue. Once citizens are informed and ready to act, they are among the most effective voices at getting decision makers to act as well. Not only will greater engagement by decision makers and elected leaders lead to more familiarity of the issue, it will also create a positive feedback in which solutions are ever more tuned to local needs and priorities.

\section{CONCLUSION}

While more remains to be known, it is becoming increasingly urgent that governments commit to taking action to address ocean acidification. Especially in light of the 2018 IPCC Special Report on Global Warming of $1.5^{\circ} \mathrm{C}$, it is abundantly clear that local, regional and international efforts to reduce carbon dioxide emissions and adapt to unavoidable changes are essential to fully prepare for the impacts of a changing ocean.

Through such commitments, governments are more effectively able to unleash and direct much needed resources to reducing the sources of acidifying pollutants, to sharing information about the impacts of ocean acidification regionally, and to improving knowledge of how to adapt to unavoidable changes while building resilience in marine ecosystems.

In the future, the path connecting science to action will be increasingly well-trod by the OA community, as the topic continues to identify ecosystem impacts that will also impact human communities (Gattuso et al., 2015). Partnerships, such as those supported by NOAA, and external entities like the OA Alliance are creating networks among communities previously not connected. These entities are facilitating the development of climate resilience frameworks that help communities start the conversation about what elements of the future need to be planned for, and how governments can build upon existing structures and policies (e.g., CA OA action plan example).

Science is advancing and providing increasingly societally relevant answers: monitoring systems are widespread and growing, and our understanding of ecosystem impacts and the food web is also growing. The interaction of the two is being connected with new models such as ecosystem models and integrated assessment models. Questions relevant to decisionmakers are increasingly being answered with these new model systems (e.g., Kaplan et al., 2010; Punt et al., 2014; Cooley et al., 2015; Siedlecki et al., 2016; Rheuban et al., 2018).

Continued effort on this front will be critical to engage support from decision-makers who fund the work, put it into 
use, and integrate it into the existing body of environmental management practices.

Working together we can we can increase global attention on actions that address the causes of ocean acidification and changing ocean conditions, as well as assist governments in establishing a set of actions that will reduce future impacts to our coastal communities, economies, and the health of our oceans. The knowledge-to-action Pipeline is a key component of this future vision.

\section{AUTHOR CONTRIBUTIONS}

JC provided the overall guidance and executive editing for the manuscript and wrote the sections introduction, discussion, and conclusion, contributed content to case studies, and designed the figures. All authors provided text input and editing. Content for section 1 was also provided by JN and TKl. JT led collaborative writing for sections $2.1,2.4$, and 3 with assistance from JN and TKl. AH led CAN representatives DD, KG, TKi, TKl, JoM, JaM, ELS, EO, GS, JV-D, and LW for section 2.2. HG-S developed section 2.3 with support from JC, CC, KA-S, EJ, DJ, and ES. SC contributed extensively to sections $2.4,3$, and led section 4.1 .

\section{FUNDING}

All authors gratefully acknowledge the support of their home institutions. The Coastal Acidification Networks and their contributions to this manuscript were funded in part by the NOAA Ocean Acidification Program grants to regional associations of the Integrated Ocean Observing System (Alaska Ocean Acidification Network: NA16NOS0120027 to the Alaska Ocean Observing System; California Current Acidification Network: NA11NOS0120032 to the Monterey Bay Aquarium Research Institute and the Central and Northern California

\section{REFERENCES}

Albright, R., and Cooley, S. (2017). "A solutions-based approach for coral reefs under OA: adaptation and mitigation," in Proceedings of the Discussion paper for "Fourth International Workshop: Bridging the Gap between Ocean Acidification and Economic Valuation," 15-17 October 2017, (Monaco: Monaco Science Center), 40.

AMAP (2018). AMAP Assessment 2018: Arctic Ocean Acidification. Troms: Arctic Monitoring and Assessment Programme (AMAP), 187.

Barton, A., Hales, B., Waldbusser, G., Langdon, C., and Feely, R. A. (2011). The Pacific oyster, Crassostrea gigas, shows negative correlation to naturally elevated carbon dioxide levels: implications for near-term ocean acidification effects. Limnol. Oceanogr. 57, 698-710. doi: 10.4319/lo.2012.57. 3.0698

Barton, A., Waldbusser, G. G., Feely, R. A., Weisberg, S. B., Newton, J. A., Hales, B., et al. (2015). Impacts of coastal acidification on the Pacific Northwest shellfish industry and adaptation strategies implemented in response. Oceanography 28, 146-159. doi: 10.5670/oceanog.2015.38

Chan, F., Boehm, A. B., Barth, J. A., Chornesky, E. A., Dickson, A. G., Feely, R. A., et al. (2016). The West Coast Ocean Acidification and Hypoxia Science Panel: Major Findings, Recommendations, and Actions. Oakland, CA: California Ocean Science Trust. doi: 10.5670/oceanog.2015.38
Ocean Observing System; Gulf of Mexico Coastal Acidification Network, \#NA16NOS0120018, to the Gulf of Mexico Coastal Ocean Observing System; Mid-Atlantic Coastal Acidification Network: NA16NOS0120020 to the Mid-Atlantic Regional Association Coastal Observing System; Northeast Coastal Acidification Network: NA16NOS0120023 to the Northeastern Regional Association of Coastal Ocean Observing; Southeast Ocean and Coastal Acidification Network: NA16NOS0120028 to Southeast Coastal Ocean Observing Regional Association). Support was also provided in part by the Washington Sea Grant, University of Washington pursuant to the NOAA Award \#NA18OAR4170095. The views expressed herein are those of the authors and do not necessarily reflect the views of the NOAA or any of its subagencies.

\section{ACKNOWLEDGMENTS}

The success of this review involved a large team of dedicated collaborators across multiple networks. This would not have been possible without the support of the NOAA Ocean Acidification Program, the Ocean Acidification Information Exchange, the Washington Ocean Acidification Center, the Global Ocean Acidification Observing Network, and the Aquatic Climate Change Adaptation Services Program (ACCASP) through the Department of Fisheries and Oceans, Canada. We gratefully acknowledge the diverse membership in these networks, including the voices of scientists, decision makers and legislators at multiple scales, commercial stakeholders, local residents and small businesses, and the native, tribal, and First Nations communities who share their traditional knowledge and advocate for cultural protection and resilience. Our special thanks to the CAN steering committees and committee members for their day-to-day work in understanding and responding to ocean acidification on the local level. This manuscript is PMEL contribution \#4925.

Cheung, W. W. L., Pinnegar, J., Merino, G., Jones, M. C., and Barange, M. (2012). Review of climate change impacts on marine fisheries in the U.K. and Ireland. Aquat. Conserv. 22, 368-388. doi: 10.1002/aqc.2248

Clements, J. C., and Chopin, T. (2016). Ocean acidification and marine aquaculture in North America: potential impacts and mitigation strategies. Rev. Aquacult.9, 326-341. doi: 10.1111/raq/12140

Cooley, S. R., and Doney, S. C. (2009). Anticipating ocean acidification's economic consequences for commercial fisheries. Environ Res Lett 4: 024007. doi: 10. 1088/1748-9326/4/2/024007

Cooley, S. R., Ono, C. R., Melcer, S., and Roberson, J. (2016). Community-level actions that can address ocean acidification. Front. Mar. Sci. 2:128. doi: 10.3389/ fmars.2015.00128

Cooley, S. R., Rheuban, J. E., Hart, D. R., Luu, V., Glover, D. M., Hare, J. A., et al. (2015). An integrated assessment model for helping the United States sea scallop (Placopecten magellanicus) fishery plan ahead for ocean acidification and warming. PLoS One 10:e0124145. doi: 10.1371/journal.pone.0124145

Cottrell, R. S., Fleming, A., Fulton, E. A., Nash, K. L., Watson, R. A., and Blanchard, J. L. (2018). Considering land-sea interactions and trade-offs for food and biodiversity. Glob. Chang. Biol. 24, 580-596. doi: 10.1111/gcb.13873

Cross, J. N., Mathis, J. T., Pickart, R. S., and Bates, N. R. (2018). Formation and transport of corrosive water in the Pacific Arctic region. Deep Sea Res. II 152, 67-81. doi: 10.1016/j.dsr2.2018.05.020 
Dupont, S., Hall, E., Calosi, P., and Lundve, B. (2014). First Evidence of Altered Sensory Quality in a Shellfish Exposed to Decreased $p H$ Relevant to Ocean Acidification. Available at: https://bioone.org/journals/Journal-ofShellfish-Research/volume-33/issue-3/035.033.0320/First-Evidence-of-Altered -Sensory-Quality-in-a-Shellfish-Exposed/10.2983/035.033.0320.full (accessed December 21, 2018).

Fabry, V. J., McClintock, J. B., Mathis, J. T., and Grebmeier, J. M. (2009). Ocean Acidification at high latitudes: the bellwether. Oceanography 22, 160-171. doi: 10.5670/oceanog.2009.105

Fabry, V. J., Seibel, B. A., Feely, R. A., and Orr, J. C. (2008). Impacts of ocean acidification on marine fauna and ecosystem processes. ICES J. Mar. Sci. 65, 414-432. doi: 10.1093/icesjms/fsn048

Feely, R. A., Klinger, T., Newton, J., and Chadsey, M. (2012). Scientific summary of ocean acidification in Washington State Marine Waters. NOAA ORR Special Report. Lacey, WA: Washington State Department of Ecology, 157.

Francis Pan, T. C., Applebaum, S. L., and Manahan, D. T. (2015). Experimental ocean acidification alters the allocation of metabolic energy. Proc. Natl. Acad. Sci. U.S.A. 112, 4696-4701. doi: 10.1073/pnas.141696 7112

Garcia, S. M., and Rosenberg, A. A. (2010). Food security and marine capture fisheries: characteristics, trends, drivers, and future perspectives. Philos. Trans. Royal. Soc. B 365, 2869-2880. doi: 10.1098/rstb.2010.0171

Gattuso, J.-P., and Hansson, L. (2011). Ocean Acidification. New York, NY: Oxford University Press Inc., 408.

Gattuso, J.-P., Magnan, A., Bille, R., Cheung, W. W. L., Howes, E. L., Joos, F., et al. (2015). Contrasting futures for ocean and society from different anthropogenic $\mathrm{CO}_{2}$ emissions scenarios. Science 349:aac4722. doi: 10.1126/science.aac4722

Gledhill, D. K., White, M. M., Salisbury, J., Thomas, H., Mlsna, I., Liebman, M., et al. (2015). Ocean and coastal acidification off New England and Nova Scotia. Oceanography 28, 182-197. doi: 10.5670/oceanog.2015.41

Guinotte, J. M., and Fabry, V. J. (2008). Ocean Acidification and its potential effects on marine ecosystems. Ann. N. Y. Acad. Sci 1134, 320-342. doi: 10.1196/annals. 1439.013

Hoegh-Guldberg, O., Poloczanska, E. S., Skirving, W., and Dove, S. (2017). Coral reef ecosystems under climate change and ocean acidification. Front. Mar. Sci. 4:20. doi: 10.3389/fmars.2017.00158

Hughes, T. P., Barnes, M. L., Bellwood, D. R., Cinner, J. E., Cumming, G. S., Jackson, J. B. C., et al. (2017). Coral reefs in the Anthropocene. Nature 546, 82-90. doi: 10.1038/nature22901

International Alliance to Combat Ocean Acidification (2016). The International Alliance to Combat Ocean Acidification: A Global Call to Action. San Diego, CA: Founding Members of the International Alliance to Combat Ocean Acidification, 3 .

International Alliance to Combat Ocean Acidification (2017). The Action Toolkit: Building your Ocean Acidification Action Plan. San Diego, CA: International Alliance to Combat Ocean Acidification, 7.

IPCC (2013). Climate Change 2013: The Physical Science Basis. Contribution of Working group I to the Fifth Assessment Report of the Intergovernmental Panel on Climate Change, eds T. F. Stocker, D. Qin, G.-K. Plattner, M. Tignore, S. K. Allen, J. Boschung, et al. (Cambridge: Cambridge University Press), 1535. doi: 10.1017/СBO9781107415324

IPCC (2014). Climate Change 2014: Synthesis Report. Contribution of Working Groups I, II, and III to the Fifth Assessment Report on the Intergovernmental Panel on Climate Change Core Writing Team, eds R. K. Pachauri and L. A. Meyer (Geneva: IPCC), 151.

Jewett, L., DeGradpre, M., Graco, M., Tilbrook, B., Kapsenberg, L., Pelejero, C., et al. (2019). The global ocean acidification observing network: a worldwide collaborative approach to address ocean change serving science and society. Front. Mar. Sci.

Johnson, J., Bell, J., and Gupta, A. S. (2015). Pacific Islands Ocean Acidification and Vulnerability Assessment. Apia, Samoa: Secretariat of the Pacific Regional Environment Program (SPREP). 41. Available at https://www.sprep.org/ publications/pacific-islands-ocean-acidification-vulnerability-assessment (accessed December 21, 2018).

Kaplan, I. C., Levin, P. S., Burden, M., and Fulton, E. A. (2010). Fishing catch shares in the face of global change: a framework for integrating cumulative impacts and single-species management. Can. J. Fish Aquat. Sci. 67, 1968-1982. doi: $10.1139 / \mathrm{F} 10-118$
Kroeker, K. J., Kordas, R. L., Crim, R. N., and Singh, G. G. (2010). Meta-analysis reveals negative yet variable effects of ocean acidification on marine organisms. Ecol. Lett. 13, 1419-1434. doi: 10.1111/j.1461-0248.2010.01518.x

Lam, V. W. Y., Cheung, W. W. L., and Sumalia, U. R. (2014). Marine capture fisheries in the Arctic: winners or losers under climate change and ocean acidification? Fish and Fisheries 17, 335-357. doi: 10.1111/faf.12106

Le Quéré, C., Mariarty, R., Andrew, R. M., Peterso, G. P., Clais, P., Friedlingstein, P., et al. (2014). Global carbon budget 2014. Earth Syst. Sci. Data Discussions 7, 521-610. doi: 10.5194/essdd-7-521-2014

Le Quesne, W. J. F., and Pinnegar, J. K. (2011). The potential impacts of ocean acidification: scaling from physiology to fisheries. Fish and Fisheries 13, 333344. doi: 10.1111/j.1467-2979.2011.00423.x

Lemasson, A. J., Hall-Spencer, J. M., Kuri, V., and Knights, A. M. (2019). Changes in the biochemical and nutrient composition of seafood due to ocean acidification and warming. Mar. Environ. Res. 143, 82-92. doi: 10.1016/j.marenvres.2018.11. 006

Long, W. C., Swiney, K. M., and Foy, R. J. (2013a). Effects of ocean acidification on the embryos and larvae of red king crab, Paralithodes camtschaticus. Mar. Pollut. Bull. 69, 38-47. doi: 10.1016/j.marpolbul.2013.01.011

Long, W. C., Swiney, K. M., Harris, C., Page, H. N., and Foy, R. S. (2013b). Effects of ocean acidification on juvenile red king crab (Paralithodes camtschaticus) and tanner crab (Chionoecetes bairdi) grwoth, condition, calcification, and survival. PLoS One 8:e60959. doi: 10.1371/journal.pone.0060959

Lynn, K., Daigle, J., Hoffman, J., Lake, F., Michelle, N., Ranco, D., et al. (2013). The impacts of climate change on tribal traditional foods. Climat. Change 120, 545-556. doi: 10.1007/s10583-013-0736-731

Marshall, K. N., Kaplan, I. C., Hodgson, E. E., Hermann, A., Busch, D. S., McElhany, P., et al. (2017). Risks of ocean acidification in the California Current food web and fisheries: ecosystem model projects. Glob. Chang. Biol. 23, 1525-1539. doi: $10.1111 /$ gcb. 13594

Mathis, J. T., Cooley, S. R., Lucey, N., Colt, S., Ekstrom, J., Hurst, T., et al. (2015). Ocean acidification risk assessment for Alaska's fishery sector. Prog. Oceanogr. 136, 71-91. doi: 10.1016/j.pocean.2014.07.001

McDowell Group (2017). The Economic Value of Alaska's seafood Industry. Anchorage, AK: McDowell Group. Available at: https://www.mcdowellgroup. net/wp-content/uploads/2017/10/ak-seadfood-impacts-sep2017-final-digitalcopy.pdf

Metcalf, V. (ed.) (2015). A Business Plan for Sustainability. Alaska Eskimo Walrus Commission. 25. Available at: http://eskimowalruscommission.org/wp-content/ uploads/2016/01/FINAL-EWC-Business-Plan-1-6-16.pdf (accessed December 21, 2018).

Munday, P. L., Dixson, D. L., Donelson, J. M., Johnes, G. P., Pratchett, M. S., Devitsina, G. V., et al. (2009). Ocean acidification impairs olfactory discrimination and homing ability of a marine fish. PNAS 106, 1848-1852. doi: 10.1073/pnas.0809996106

Narita, D., Rehdanz, K., and Tol, R. S. J. (2012). Economic costs of ocean acidification: a look into the impacts on global shellfish production. Climat. Change 113, 1049-1063. doi: 10.1007/s10584-011-0383-383

National Marine Fisheries Service (2012). Fisheries of the United States 2012. Fisheries Statistics Division, National Oceanic and Atmospheric Administration, Report NO: 2012. Silver Spring, MD: National Marine Fisheries Service. doi: 10.1007/s10584-011-0383-3

Newton, J. A., Feely, R. A., Jewett, E. B., Williamson, P., and Mathis, J. T. (2015). The Global Ocean Acidification Network: Requirements and Governance Plan, Second Edn. Vienna: IAEA, 57.

Orr, J. C., Fabry, V. J., Aumont, O., Bopp, L., Doney, S. C., Feely, R. A., et al. (2005). Anthropogenic ocean acidification over the twenty-first century and its impacts on calcifying organisms. Nature 437, 681-686. doi: 10.1038/nature04095

Ou, M., Hamilton, T. J., Eom, J., Lyall, E. M., Gallup, J., Jiang, A., et al. (2015). Responses of pink salmon to $\mathrm{CO}_{2}$-induced aquatic acidification. Nat. Clim. Chang. 5, 950-955. doi: 10.1038/nclimate2694

Phillips, J., Berry, W., Carter, H., Whiteman, L., and Chornesky, L. (eds) (2018). State of California Ocean Acidification Action Plan. San Diego, CA: California Ocean Protection Council. doi: 10.1038/nclimate2694

Pinnegar, J., Watt, T., and Kennedy, K. (2012). CCRA Risk Assessment for the Marine and Fisheries Sector. UK 2012 Climate Change Risk assessment. London: Department for Environment, Food and Rural Affairs,. doi: 10.1038/ nclimate2694 
Punt, A. E., Poljak, D., Dalton, M. G., and Foy, R. J. (2014). Evaluating the impact of ocean acidification on fishery yields and profits: the example of red king crab in Bristol Bay. Ecol. Model. 285, 39-53. doi: 10.1016/j.ecolmodel.2014. 04.017

Rheuban, J. E., Doney, S. C., Cooley, S. R., and Hart, D. R. (2018). Projected impacts of future climate change, ocean acidification, and management of the US Atlantic sea scallop (Placopecten magellanicus) fishery. PLoS One 13:e0203536. doi: 10.1371/journal.pone.0203536

Richards, R. G., Davidson, A. T., Meynecke, J.-O., Beattie, K., Hernaman, V., Lynam, T., et al. (2015). Effects and mitigations of ocean acidification on wild aquaculture and prawn fisheries an Queensland, Australia. Fish. Res. 161, 42-56. doi: 10.1016/j.fishres.2014.06.013

Seung, C. K., Dalton, M. G., Punt, A. E., Poljak, D., and Foy, R. (2015). Economic impacts of changes in an Alaska crab fishery from ocean acidification. Clim. Chang. Econ. 6, 1-35. doi: 10.1142/S20100078155 00177

Siedlecki, S. A., Kaplan, I. C., Hermann, A. J., Nguyen, T. T., Bond, N. A., Newton, J. A., et al. (2016). Experiments with seasonal forecasts of ocean conditions for the Northern region of the California Current upwelling system. Nat. Sci. Rep. 6:27203. doi: 10.1038/srep27203

Simpson, S. D., Munday, P. L., Wittenrich, M. L., Manassa, R., Dixson, D. L., Gagliano, M., et al. (2011). Ocean acidification erodes crucial auditory behavior in a marine fish. Biol. Lett. 7, 917-920. doi: 10.1098/rsbl.2011. 0293

Speers, A. E., Besedin, E. Y., Parlardy, J. E., and Moore, C. (2016). Impacts of climate change and ocean acidification on coral reef fisheries: an integrated ecological-economic model. Ecol. Econ. 12, 33-43. doi: 10.1016/j.ecolecon.2016. 04.012

Tilbrook, B., Jewett, E. B., DeGrandpre, M. D., Hernandez-Ayon, J. M., Feely, R. A., Gledhill, D. K., et al. (2019). An enhanced ocean acidification observing network: from people to technology to data synthesis and information exchange. Front. Mar. Sci. doi: 10.3389/fmars.2019.00337
Washington State Blue Ribbon Panel on Ocean Acidification (2012). "Ocean acidification: from knowledge to action," in Washington State's Strategic Response, eds H. Adelsman and L. W. Binder (Olympia, WA: Washington Department of Ecology), 158.

Washington State Blue Ribbon Panel on Ocean Acidification (2017). An updated plan to address ocean acidification in Washington State. Olympia, WA: Washington Department of Ecology.

Wassillie, K., and Poe, M. (2015). Pacific Walrus and Coastal Alaska Native Subsistence Hunting: Considering Vulnerabilities from Ocean Acidification. Piscataway, NJ: IEEE Earthzine.

Yañez, E., Lagos, N. A., Norambuena, R., Silva, C., Letelier, J., Much, K.-P., et al. (2017). "Impacts of climate change on marine fisheries and aquaculture in Chile," in Climate Change Impacts on Fisheries and Aquaculture, eds B. F. Phillips and M. Pérez-Ramírez (Hoboken, NJ: John Wiley and Sons, Ltd.), 239-332. doi: 10.1002/97811191540 51.ch10

\section{Conflict of Interest Statement: JT was employed by Cascadia Law Group.}

The remaining authors declare that the research was conducted in the absence of any commercial or financial relationships that could be construed as a potential conflict of interest.

Copyright (C) 2019 Cross, Turner, Cooley, Newton, Azetsu-Scott, Chambers, Dugan, Goldsmith, Gurney-Smith, Harper, Jewett, Joy, King, Klinger, Kurz, Morrison, Motyka, Ombres, Saba, Silva, Smits, Vreeland-Dawson and Wickes. This is an openaccess article distributed under the terms of the Creative Commons Attribution License (CC BY). The use, distribution or reproduction in other forums is permitted, provided the original author(s) and the copyright owner(s) are credited and that the original publication in this journal is cited, in accordance with accepted academic practice. No use, distribution or reproduction is permitted which does not comply with these terms. 